\title{
PAZ ENTRE OS HOMENS: A TOLERÂNCIA E VOLTAIRE REVISITADO
}

\author{
PEACE AMONG MEN: THE TOLERANCE AND VOLTAIRE REVISED
}

\author{
Júnio Cézar da Rocha Souza ${ }^{1}$ \\ (junio.junio@bol.com.br)
}

“[...] Na discussão se Cristo seria homooúsio ou homoioúsois, ou seja, criatura igual ou semelhante

a Deus, a letra i custou a vida de milhares".

Hegel ${ }^{2}$.

\section{RESUMO}

No Tratado sobre a tolerância, obra de 1763 , Voltaire se debruça sobre um caso que merecia toda a atenção de seu tempo e, igualmente, da posteridade: o caso Jean Calas. As intempestivas acusações, sem nenhuma mediação da razão, tornaram o ocorrido um prenúncio de tantos outros que viriam pela frente. O presente artigo propõe uma revisitação ao texto de Voltaire, para que o tema da tolerância seja retomado e rediscutido. Com vistas a transcender limiares que obnubilam a razão e sufocam a possibilidade de um convívio pacífico entre os homens, uma discussão a partir das Luzes se coloca oportuna para uma avaliação dos matizes da intolerância, esta que se perpetua, e para a retomada de sua antípoda, a tolerância, que nunca foi tão necessária para o século XXI nos diversos espaços de convivência dos cidadãos.

Palavras-chave: Homens; paz; tolerância; Voltaire.

\begin{abstract}
In the 1763 Treatise on Tolerance, Voltaire focuses on a case that deserved the full attention of his time, and also of posterity: the Jean Calas case. The untimely accusations, without any mediation of reason, made this a foretaste of so many others that would come ahead. The present article proposes a revision of Voltaire's text so that the theme of tolerance can be resumed and rediscussed. In order to transcend thresholds that obscures reason and stifle the possibility of a peaceful coexistence among men, a discussion from the Lights is opportune for an assessment of the nuances of intolerance, which perpetuates itself, and for the resumption of its antipodal, the tolerance, which has never been so necessary for the 21 st century in the various spaces of coexistence of citizens.
\end{abstract}

Key words: Men; Peace; tolerance; Voltaire.

\footnotetext{
${ }^{1}$ Doutorando em Filosofia pela Universidade Federal do Goiás (UFG).

CV Lattes: http://lattes.cnpq.br/1393275621693731.

${ }^{2}$ Hegel faz referência às discussões cristológicas dos primeiros séculos da história do cristianismo que diziam respeito à substância do Filho de Deus, se ele era da mesma substância do Pai ou de substância diferente. A letra grega "i”" (iota) modificava o significado da palavra que rendeu debates duradouros. (HEGEL, 2008, p.287).
} 
Introdução

O Tratado sobre a tolerância: a propósito da morte de Jean Calas de Voltaire, em sua edição de 1763, termina da seguinte maneira:

Com minhas mãos plantei os alicerces de um prédio imenso; ele era sólido e simples, todos os homens nele podiam entrar com segurança; quiseram acrescentar os ornamentos mais bizarros, mais grosseiros e mais inúteis; e o prédio começa a desmoronar por todos os lados; os homens pegam as pedras e as atiram uns contra os outros; grito-lhes: Parai, afastai esses escombros funestos que são vossa obra e habitai comigo em paz no prédio inabalável que é o meu. (VOLTAIRE, 2000, p. 137).

O texto de Voltaire se encerra com a descrição da inclinação dos homens para a intolerância. O intento do filósofo foi se debruçar sobre um caso que merecia toda a atenção de seu tempo e a demandaria igualmente da posteridade. O caso era do senhor Jean Calas, um comerciante de Toulouse de 68 anos, protestante, que foi assassinado na roda no dia 9 de março de 1762, condenado por haver supostamente enforcado um de seus filhos por conversão ao catolicismo. A intolerância, por parte não apenas das autoridades jurídicas que conduziram o caso, mas, igualmente, dos vizinhos, chama a atenção de Voltaire. A reflexão exposta no Tratado sobre a tolerância merece ser revisitada em uma época que dista temporalmente do episódio, visto que não se pode dizer o mesmo quanto aos atores que ocupam o cenário. A intolerância ainda é um tema que precisa ser recolocado repetidas vezes no debate contemporâneo, e o filtro da filosofia nunca foi tão necessário. As intempestivas acusações, sem nenhuma mediação da razão, tornaram o caso Calas um prenúncio de tantos outros que viriam pela frente. A intolerância que grassa nos muitos lugares atualmente, de feição religiosa, política, ou com contornos multifários, deve ser rediscutida do ponto de vista da necessidade de haver paz entre os homens.

O presente artigo propõe uma revisitação ao texto de Voltaire para que o tema da tolerância seja retomado e rediscutido, também, segundo a orientação proposta pelo filósofo do século XVIII. Uma discussão a partir das Luzes, com vistas a transcender barreiras que toldam a razão e sufocam a possibilidade de um convívio pacífico entre os homens, colocase oportuna para uma avaliação dos contornos da intolerância que é vista nos diversos 
espaços de convivência dos cidadãos e que precisa de uma substituta, a tolerância, noção e postura tão necessária à contemporaneidade.

\section{O homem como figura dúbia e inexplicável}

Voltaire, em um conto de 1748 chamado "Le monde comme il va", demonstra a oscilação dos homens em seus empreendimentos, mas especialmente o caráter inexplicável de suas ações tão díspares. Babuc, personagem principal do conto, foi convocado por um dos gênios que presidia os impérios do mundo, Ituriel, responsável pelo departamento da Alta Ásia. $\mathrm{O}$ anjo lhe diz que as loucuras e os excessos dos persas tinham atraído a cólera do divino. Babuc é chamado a examinar a cidade de Persépolis e prestar relatório posterior a partir do qual Ituriel tomaria a decisão de castigar ou não a cidade, pondo fim às barbáries cometidas pelos homens ou absolvendo-os com larga misericórdia.

Duas demonstrações de estupefação de Babuc parecem se harmonizar por demais com o que Voltaire encontraria no caso Calas. Babuc, diante da inconstância dos homens, pergunta: "Inexplicáveis humanos [...], como podeis reunir tanta baixeza e grandeza, tantas virtudes e crimes?" (VOLTAIRE, 1972, p. 85). O personagem se surpreende com o caráter volúvel dos homens. Depois de passar alguns momentos entre soldados dos acampamentos persa e hindu, vendo ações tanto de um grupo quanto de outro, não sabe distinguir se são homens de verdade ou animais ferozes. Contempla desprendimento, grandeza de alma, humanidade, posturas que o comovem, mas não demora a observar excessos transidos de horror. ${ }^{3}$

Enquanto seu conhecimento de Persépolis aumenta, Babuc não tem saída a não ser reconhecer, diante do que vê na cidade: “Ó costumes! Ó desgraçada cidade! [...] eis o cúmulo da desordem. Os que assim compraram o direito de julgar com certeza vendem os seus

\footnotetext{
${ }^{3}$ Voltaire aqui encontra apoio em uma afirmação de Rousseau, seu contemporâneo, que também apresenta essa dubiedade no homem. Ao falar sobre a piedade no Discurso sobre a origem e os fundamentos da desigualdade entre os homens, com o fito de exaltá-la nessa complexa alternância que ocorre no homem, o filósofo genebrino assevera: "Tal o movimento puro da natureza, anterior a qualquer reflexão; tal a força da piedade natural que até os costumes mais depravados têm dificuldade em destruir, porquanto se vê todos os dias, em nossos espetáculos, emocionar-se e chorar por causa das infelicidades de um desafortunado, aquele mesmo que, se estivesse no lugar do tirano, agravaria ainda mais os tormentos de seu inimigo, como o sanguinário Sila, tão sensível aos males que não tinha causado, ou aquele Alexandre de Fers, que não ousava assistir à representação de uma tragédia, temendo que o vissem chorar com Andrômaca e Príamo, enquanto ouvia sem emoção os gritos de tantos cidadãos que, por sua ordem, eram degolados cada dia" (ROUSSEAU, 1999, p. 77).
} 
julgamentos. Não vejo aqui senão abismos de iniquidade" (VOLTAIRE, 1972, p. 88). À medida que o momento da escrita do relatório que deve entregar aos deuses se avizinha, Babuc vê assomando ao seu coração apenas perspectivas negativas a respeito daqueles de quem deve examinar o comportamento e a vida. A loucura é vista na vida daqueles que lidam com a sabedoria, as intrigas ocupam o espaço na rotina daqueles que haviam renunciado ao mundo, o orgulho é a medalha dos que proclamam a humildade e o desapego. A conclusão do relatório não poderia ser diferente; Babuc sabe que Ituriel tem boas razões para destruir toda aquela espécie.

Ao retornar para casa, ocupando-se dos últimos momentos para a escrita de seu relatório aos anjos, entretém-se com os livros e banqueteia com alguns letrados a fim de distrair-se, mas sua decepção é tamanha com os convivas. Observa neles também maledicência, covardia, mau gosto, inveja, baixeza. Sai para caminhar após seu rompante de decepção e é apresentado a um velho letrado que muito se diferencia dos que com ele jantaram anteriormente. Partilha com o ancião sua experiência amarga com o que lera e ouvira. Do veterano lhe vem uma espécie de epifania e consolo inestimável. O sábio lhe diz as seguintes palavras:

- O senhor leu coisas bastante desprezíveis - disse-lhe o sábio letrado. - Mas em todas as épocas, e em todos os países, e em todos os gêneros, sempre formiga o mau e escasseia o bom. E se o senhor recebeu em casa o rebotalho do pedantismo é porque, em todas as profissões, o que há de mais indigno de aparecer é sempre o que se apresenta com maior impudência. Os verdadeiros sábios vivem entre si, retirados e tranquilos; há ainda, em nosso meio, homens e livros dignos de lhe ocupar a atenção. (VOLTAIRE, 1972, p. 92)

Voltando-se para os aspectos apetecíveis que se podem encontrar nos seres humanos, a reflexão de Babuc contorna a experiência em Persépolis de maneira que seu relatório se constitui de maneira diferente. É claro que, nesse vai-e-vem experimentado por Babuc, sua própria condição é demonstrada. O ser humano é dúbio, complexo, inexplicável. As palavras não conseguiriam expressar o conteúdo do que o relator tem a dizer aos deuses. Figura, então, uma forma sui generis de informar Ituriel:

Eis como se houve para apresentar esse relatório. Mandou fazer no melhor fundidor da cidade uma estatueta composta de todos os metais, das terras e pedras mais preciosas e mais vis; e levou a Ituriel. - Destruirias - disse ele - esta linda estátua, porque não é toda de ouro e diamantes? Ituriel soube compreender; nem mesmo pensou em corrigir Persépolis, e resolveu deixar o mundo como estava. Pois, disse ele, se nem tudo está bem, tudo é passável. Deixou, pois, subsistir Persépolis; e longe estava Babuc de se queixar, como Jonas, que se agastou por não terem destruído Nínive. Mas 
depois que a gente passou três dias dentro de uma baleia, não se sente de tão bom humor como depois de haver estado na ópera, na comédia, e de ter jantado em boa companhia. (VOLTAIRE, 1972, p. 96-97, grifo do autor)

O relatório em forma de escultura revela, com estética impactante, a mescla que compõe o homem, do ponto de vista do filósofo. A postura flutuante, a combinação de coisas boas e ruins demonstram a natureza dúbia desse homem que o coloca sob a sombra da complexidade. É justamente esse homem, que ora se apresenta com altruísmo galopante, ora com uma desprezível postura intolerante, que será objeto de observação de Voltaire no famoso caso Calas.

\section{O caso Calas e a questão da tolerância}

Voltaire observou numa ocasião bem específica, diante do caso Jean Calas, esses “inexplicáveis humanos". Uma brutalidade entre vizinhos, uma rixa religiosa que se estendia desde o século XVI, da qual, mesmo no Século das Luzes, as trevas da intolerância ainda não haviam sido dissipadas completamente. Intolerância produzida por religiosos que cultivavam sua fé entre seus pares e na vida privada, desempenhando suas virtudes e procurando demonstrá-las ao seu próximo, desde que esse próximo não fosse de religião contrária à sua. Voltaire não tomava partido pelo protestantismo; ele o fazia pela razão, pela filosofia, que segundo ele já havia prestado um enorme serviço aos homens. Segundo o filósofo: “A filosofia, a mera filosofia, essa irmã da religião, desarmou mãos que a superstição por muito tempo havia ensanguentado; e o espírito humano, ao despertar de sua embriaguez, espantou-se com os excessos a que o fanatismo o havia levado." (VOLTAIRE, 2000, p. 23). A acusação sem o devido cuidado, por ímpeto religioso e sem o correto peneiramento da razão, torna o caso Calas repugnante ao olhar de Voltaire. Quando a intolerância é vista grassando em um determinado tempo e contexto, parece ser algo natural a que se deve recorrer, quando o outro for julgado inconveniente ou trilhando caminho diverso. Seria, então, a intolerância um direito natural? Voltaire afirma que "o direito natural é aquele que a natureza indica a todos os homens" (VOLTAIRE, 2000, p. 33). E não parece que a natureza indicasse ao homem a intolerância como prática benéfica para todos. Ao contrário, o princípio universal que impera é "não faças o que não gostarias que te fizessem" (VOLTAIRE, 2000, p. 33). A partir 
disso, nenhum homem poderia dizer, como afirma Voltaire:

\begin{abstract}
"Acredita no que acredito e no que não podes acreditar, ou morrerás." É o que dizem em Portugal, na Espanha, em Goa. Atualmente limitando-se a dizer, em alguns países: "Crê, ou te abomino; crê, ou te farei todo o mal que puder; monstro, não tens minha religião, logo não tens religião alguma: cumpre que sejas odiado por teus vizinhos, tua cidade, tua província”. (VOLTAIRE, 2000, p. 33)
\end{abstract}

A natureza não disporia todas as coisas a essa desordem, ao capricho de cada um, ajuizando quem quer que seja sem o mínimo de ponderação e respeito pelo outro. Disso se conclui, segundo Voltaire, que "o direito da intolerância é, pois, absurdo e bárbaro; é o direito dos tigres, e bem mais horrível, pois os tigres só atacam para comer, enquanto nós exterminamonos por parágrafos" (VOLTAIRE, 2000, p. 34).

A intolerância, longe de cumprir seu papel - pensado a partir de um segmento religioso que não tolera seu discordante e quer forçadamente vê-lo professando sua fé -, produz rebeldes e hipócritas (VOLTAIRE, 2000, p. 63). Quando a intolerância se impõe e suas sanções vêm como corolário inevitável, a religião perde seu espaço e ultrapassa seus limites. Sendo assim, segundo Romilly, no verbete "tolerância" da Encyclopédie, “[...] a religião persuade, não comanda" (ROMILLY FILHO, 2015, p. 363). Quando a religião quer comandar por meio de suas opiniões, ou qualquer outro segmento não necessariamente religioso, fazendo com que se submetam todas as ideias contrárias, usará de expedientes para que o outro não seja tolerado. Por isso, Diogo Aurélio, em sua obra Um fio de nada: ensaio sobre a tolerância, afirma:

Assim sendo, a imposição de uma opinião ou de uma norma de comportamento jamais poderá reivindicar qualquer espécie de legitimidade e remeterá sempre para o domínio da violência. Dito de outro modo, por natureza, cada um tem o direito de viver como achar melhor e de sustentar a "verdade" que entender, ainda que esta não passe, para todos os outros, de um simples erro. (AURÉLIO, 1997, p. 29)

A reivindicação da tolerância não visa a uniformizar o pensamento humano, apenas requer que a pluralidade seja admitida sem que o diferente sofra punição por sua opinião diversa. É preciso concordar com Romilly, admitindo que, assim como não é possível dar uma feição única aos corpos dos homens, tampouco o seria no campo dos espíritos, espaço no qual sempre permaneceremos em litígios: "A diversidade das opiniões subsistirá sempre entre os homens; a história do espírito humano é uma prova contínua disso e o projeto mais quimérico seria o de levar os homens a uma uniformidade de opiniões" (ROMILLY FILHO, 2015, p. 364-365). 
O problema não está no campo multifário das opiniões. Ele existe e será inextinguível. O problema reside quando esse espaço começa a ser reduzido e se perde completamente, dando espaço apenas a uma perspectiva, a um pensamento monolítico que não se abre para o contraditório. Mas não é somente a religião que pode perpetrar práticas intolerantes. $\mathrm{O}$ uso inadequado que se faz da razão também pode produzir o interesse pela subserviência do pensamento do outro. A razão é um filtro por demais importante para que as práticas sejam acrisoladas e o componente intolerante seja retirado; contudo, uma postura prepotente e desajustada poderá produzir intolerância tal como o faz um religioso que manqueja da razão. Ainda Romilly, sobre essa matéria, menciona:

Quem consegue ver, sem dor e sem indignação, que a própria razão que deveria nos levar à indulgência e à humanidade, à insuficiência de nossas luzes e à diversidade de nossas opiniões seja precisamente aquela que com mais fúria nos divide? Nós nos tornamos os acusadores e os juízes de nossos semelhantes; são por nós citados em nossos tribunais com arrogância; exercemos sobre seus sentimentos a inquisição mais odiosa; o erro não pode encontrar complacência aos nossos olhos, como se fôssemos infalíveis. (ROMILLY FILHO, 2015, p. 353)

A razão pode claudicar. Ela pode ser usada indevidamente e, no lugar de um espaço adequado para se tolerar o outro, ouvindo-o em seu discurso, abre-se apenas espaço para aquele que pensa orientado por determinado ponto de vista, fundamentado pretensamente na "razão".

Será que Voltaire, por azo do fervor do caso Calas, abriria espaço para algum tipo de intolerância? Será que a intolerância seria permitida em algum caso ou se deve permitir tudo de todos em toda e qualquer situação? Voltaire não concordaria com isso, com uma tolerância sem medida. Ele admitia punição. Os erros devem ser punidos, mas, para que o governo possa punilos, eles precisam se constituir como crimes. E quando um erro se torna um crime? A resposta de Voltaire é bem direta e sem fundamentação larga: os erros "só são crimes quando perturbam a sociedade" (VOLTAIRE, 2000, p. 105). A sociedade é perturbada a partir do momento em que esses erros inspiram o fanatismo. Isso quer dizer que merecem tolerância apenas aqueles que não se afiançam no fanatismo, aqueles que não perturbam o bom convívio em sociedade, espaço onde deve prevalecer o respeito mútuo e a agência da harmonia.

Voltaire menciona um caso que ilustra sua admissão de que a intolerância ao fanatismo parece ser a sua única aplicação razoável:

Um dos mais espantosos exemplos de fanatismo foi uma pequena seita na Dinamarca, cujo princípio era o melhor do mundo. Esses crentes queriam obter a salvação eterna de seus irmãos; mas as 
consequências desse princípio eram singulares. Eles sabiam que todos os recémnascidos que morrem sem batismo são condenados e que os que têm a felicidade de morrer imediatamente após receberem o batismo gozam da glória eterna. Saíam, pois, a estrangular os meninos e meninas recém-batizados que encontrassem. Certamente, era fazer-lhes o maior bem possível: a uma só vez eram preservados do pecado, das misérias desta vida e do inferno, e enviados infalivelmente ao céu. Mas essas pessoas caridosas não consideravam que não é permitido fazer um pequeno mal tendo em vista um grande bem; que não tinham nenhum direito sobre a vida dessas criancinhas; que a maior parte dos pais e mães são suficientemente materialistas para preferirem ter junto deles seus filhos e filhas do que vê-los estrangulados para ir ao paraíso, e que, em uma palavra, o magistrado deve punir o homicídio, ainda que feito com boa intenção. (VOLTAIRE, 2000, p. 106)

Embora Voltaire condene o fanatismo e o indique como único objeto da intolerância, ele não faz o mesmo com a religião, embora esta seja objeto de boa parte de sua crítica quanto ao caso Calas. A religião serve como um freio em toda sociedade estabelecida (VOLTAIRE, 2000, p. 113). Ela é necessária, pois, enquanto as leis se estabelecem contra os crimes conhecidos, a religião opera contra os crimes secretos. Contudo, a religião produz filhas, e uma delas é a superstição. É a superstição que fundamenta o fanatismo que se torna inegavelmente inútil para os povos. A superstição é uma espécie de religião sem fundamentos. Voltaire assevera que "a superstição é, em relação à religião, o que a astrologia é em relação à astronomia, a filha muito insensata de uma mãe muito sensata. Essas duas filhas subjugaram por muito tempo a terra inteira" (VOLTAIRE, 2000, p. 114).

Não obstante Voltaire não defina o que é superstição, em meio às comparações que faz, anteriormente mencionadas, ela parece ser o mesmo que uma "ignorância insolente" (VOLTAIRE, 2000, p. 116). Quando a razão é retirada, a religião se torna desidratada, desprovida de um componente fundamental, e em razão disso produz filhas deformadas. Dessa maneira, a superstição tem condições de se espraiar em vários espaços; ela não se assenta apenas em solo religioso. A superstição mais perigosa, conforme pensa Voltaire, é uma que pode ser tomada como superstição universal, qual seja, a de não aceitar a opinião do outro. Nesse caso, a razão é completamente eliminada. Está fora do espaço de diálogo. Voltaire pergunta sobre o assunto: "Mas, de todas as superstições, a mais perigosa não é a de odiar o próximo por suas opiniões? E não é evidente que seria ainda mais sensato adorar o santo umbigo, o santo prepúcio, o leite e o manto da Virgem Maria, do que detestar e perseguir seu irmão?” (VOLTAIRE, 2000, p. 116).

Essa superstição, o ódio dirigido ao outro por causa de suas opiniões, é mais insensata do que as superstições religiosas. Sofre dela, então, não apenas o religioso, mas todo aquele que se inflama contra o outro diante de sua discordância. Isso mostra 
que, embora a intolerância seja típica da ambiência religiosa, ela não faz parte apenas desse mundo. A intolerância se processa e se manifesta por meio desse homem dúbio, contraditório, volúvel, como já foi dito. Em outros âmbitos e circunstâncias o homem pode, sem muita dificuldade, evidenciar a equivocada e maléfica intolerância que tanto maltrata a convivência dos homens.

O propósito do Tratado sobre a tolerância era tornar os homens mais compassivos e doces; mais ainda, como disse o próprio autor: "Esse texto sobre a tolerância é uma petição que a humanidade apresenta muito humildemente ao poder e à prudência. Semeio um grão que algum dia poderá produzir uma grande colheita" (VOLTAIRE, 2000, p. 136). Tal propósito fora guiado pela noção de finitude humana, pelos erros dos homens, pelo caráter falho destes, pois "a natureza diz a todos os homens: Fiz todos vós nascerem fracos e ignorantes, para vegetarem alguns minutos na terra e adubarem-na com vossos cadáveres. Já que sois fracos, auxiliai-vos; já que sois ignorantes, instruí-vos e tolerai-vos.” (VOLTAIRE, 2000, p. 136). Quanto mais se perde esse senso de insignificância e igualdade nessa condição, mais portas se abrem para a intolerância, que reivindica um status privilegiado de alguns em detrimento de outros. A falta de reconhecimento da dignidade do outro enquanto agente do discurso, portador de espaço de fala também, alimenta a intolerância, demarcando mais ainda essa diminuição do outro imposta por aquele que não aceita o diferente.

Voltaire também conta uma situação curiosa, uma controvérsia que se deu na China nos primeiros anos do grande imperador Kang-hi. Na ocasião, um mandarim da cidade de Cantão entabulou uma conversa com alguns missionários que para lá foram com o intuito de anunciar sua religião. A conversa se iniciou depois de o mandarim descobrir que os religiosos se encontravam em uma disputa que mais parecia, pelo alarde que causava, tratar-se de alguém intentando contra a vida de outrem. A briga se dava entre um dinamarquês, um holandês e um jesuíta. $\mathrm{O}$ assunto era o Concílio de Trento ${ }^{4}$. Depois de ouvir do que se tratava, assim Voltaire retrata as palavras do sábio chinês:

- Isso me espanta - fez o mandarim. E voltando-se para os dois refratários: Parece-me que deveríeis respeitar as opiniões de uma grande assembleia. Não sei o que vem a ser o concílio de Trento; mas várias pessoas são sempre mais instruídas do que uma só. Ninguém deve acreditar que sabe mais do que os outros e que a razão só habita em sua cabeça. É assim que ensina nosso grande Confúcio. E se acreditais em mim, fareis muito bem em confiar na autoridade do concílio de Trento. (VOLTAIRE, 2000, p. 110).

\footnotetext{
${ }^{4}$ O Concílio de Trento foi um dos concílios ecumênicos da história da Igreja que aconteceu de 1545 a 1563. Conhecido como "Contrarreforma", o concílio produziu um conjunto de regras que foram “utilizadas pela Igreja e pelos católicos até o Vaticano II [...]” (SUFFERT, 2001, p. 271).
} 
A disputa se alongou e o mandarim, após dar ouvidos a todas as posições, conseguiu com grande esforço apaziguar a discussão com uma emblemática orientação: "Se quereis que tolerem aqui vossa doutrina, começai por não serem intolerantes nem intoleráveis" (VOLTAIRE, 2000, p. 111). A reprimenda do sábio é digna de aceitação. A intolerância desconsidera o outro sem que haja chances de defesa e de pronunciamento. Voltaire parece querer levar às últimas consequências o tema, quando continua o relato informando que após a audiência com o mandarim ter se encerrado, ao sair, o jesuíta encontrou um missionário dominicano e declarou que havia saído vitorioso do debate com o dinamarquês e o holandês, sob a auspiciosa mediação do mandarim. Essa afirmação foi motivo para uma querela esquentada entre o jesuíta e o dominicano, que chegaram a se agarrar pelos cabelos. Quando o mandarim foi informado do escândalo que havia acontecido, encaminhou os brigões para o cárcere. Um dos ministros do sábio lhe perguntou:

"Quanto tempo Vossa Excelência quer que eles fiquem detidos?" - Até que estejam de acordo, respondeu o mandarim. - Ah! fez o ministro, então ficarão na prisão pelo resto da vida. - Pois bem, replicou o mandarim, até que se perdoem. - Eles jamais se perdoarão, disse o outro; eu os conheço. - Pois então, concluiu o mandarim, até que finjam perdoar-se. (VOLTAIRE, 2000, p. 111)

A tolerância é necessária, nem que seja fingida. Por mais que seja mera teatralidade, a convivência entre os homens precisa ser harmônica. Deve existir o senso de coexistência entre os cidadãos, ainda que tenham opiniões diferentes, para que mesmo com a pluralidade de ideias haja uma convergência para aquilo que se firma como um bem comum a toda a coletividade. É justamente esse o bastião necessário entre os homens que Voltaire procura esboçar.

\section{Considerações Finais}

O caso Calas foi revisado e, no dia 9 de março de 1765, a inocência da família triunfou plenamente. Houve festa em Paris. A decisão do Parlamento de Toulouse foi declarada iníqua e abusiva, e a família condenada foi declarada inocente por parte do Conselho de Estado reunido na cidade de Versalhes. A memória do pai foi reabilitada; a família poderia reivindicar, por direito, a reparação pelos danos e perdas que os magistrados 
tolosanos provocaram, tendo estes de suprir por conta própria todas as despesas.

Voltaire encerra seu relato sobre o caso com a seguinte menção: "Esses casos são raros, mas acontecem, e são o efeito dessa triste superstição que leva as almas fracas a imputarem crimes a todo aquele que não pensa como elas" (VOLTAIRE, 2000, p. 143).

O texto de Voltaire se presentifica com uma atualidade inegável. A necessidade de haver paz entre os homens não foi uma demanda apenas do século XVIII; mostrou-se necessária anteriormente, assim como não deixou de ser imperiosa posteriormente. A intolerância que tira a paz de entre os homens, impossibilitando a convivência fraterna, não é fruto da religião simplesmente, não é por falta da razão somente; dá-se em função da superstição mais insensata, a de odiar o outro em virtude de sua opinião. Quem sabe seja oportuno ajudarmos Voltaire, pegando a semente e lançando ao solo novamente na esperança de que ela possa germinar e produzir a ceifa? Se a tarefa é aparentemente inútil em nosso tempo, quiçá acompanhemos o filósofo em sua oração, dirigindo-nos não mais aos homens, mas a Deus, em uma súplica por tolerância:

Possam todos os homens lembrar-se de que são irmãos! Que abominem a tirania exercida sobre as almas, assim como execram o banditismo que toma pela força o fruto do trabalho e da indústria pacífica! Se os flagelos da guerra são inevitáveis, não nos odiemos, não nos dilaceremos uns aos outros em tempos de paz e empreguemos o instante de nossa existência para abençoar igualmente em mil línguas diversas, do Sião à Califórnia, tua bondade que nos deu esse instante. (VOLTAIRE, 2000, p. 126)

Se é assim, não há outra coisa a fazer: resta-nos esperar os efeitos dessa oração 
Referências

AURÉLIO, Diogo Pires. Um fio de nada: ensaio sobre a tolerância. Lisboa: Edições Cosmos, 1997.

ROMILLY FILHO. Tolerância (Ordem enciclopédica, Teologia, Moral e Política). In: DIDEROT, Denis. Enciclopédia, ou Dicionário razoado das ciências, das artes e dos ofícios. Volume 4: Política / Denis Diderot, Jean le Rond d'Alembert; organização Pedro Paulo Pimenta, Maria das Graças de Souza. Tradução de Maria das Graças de Souza, Pedro Paulo Pimenta, Thomaz Kawauche. 1 ed. São Paulo: Editora Unesp, 2015. p. 351-366.

HEGEL, Georg Wilhelm Friedrich. Filosofia da História. Tradução de Maria Rodrigues e Hans Harden. 2 ed. Brasília: Editora Universidade de Brasília, 2008.

ROUSSEAU, Jean-Jacques. Discurso sobre a origem e os fundamentos da desigualdade entre os homens. Tradução de Lourdes Santos Machado. São Paulo: Editora Nova Cultural, 1999. (Os Pensadores)

SUFFERT, Georges. Tu és Pedro: santos, papas, profetas, mártires, guerreiros, bandidos. A história dos primeiros 20 séculos da Igreja fundada por Jesus Cristo. Tradução de Adalgisa Campos da Silva. Rio de Janeiro: Objetiva, 2001.

VOLTAIRE. O mundo como está: visão de Babuc escrita por ele mesmo. In: VOLTAIRE. Contos. Tradução de Mário Quintana. Porto Alegre: Abril Cultural, 1972. p. 7997.

Tratado sobre a tolerância: a propósito da morte de Jean Calas. Tradução de Paulo Neves. $2^{\text {a }}$ ed. São Paulo: Martins Fontes, 2000. 